\section{An Ecological Aspect of the Gulf Stream*}

THE view has been increasingly accepted, since first put forth by Nathansohn ${ }^{1}$, that the fertility of the sea depends upon the restoration to the surface of plant nutrients such as phosphates and nitrates liberated by the decomposition of organic matter within its depths. In shallow coastal waters the turbulence due to wind and tide, aided in high latitudes by the instability resulting from cooling in winter, suffice to maintain this part of the nutritional cycle. In the deep sea, organic matter generated in the surface as the result of photosynthetic processes appears in large part to sink to great depths before being finally oxidized to its ultimate inorganic products. This is evidenced by the increasing concentration of nitrate and phosphate (and decreasing quantity of oxygen) which is observed until depths of 800-1,000 metres are reached.

Wattenberg ${ }^{2}$ has recently listed four processes by which these materials are brought again to the surface in the Atlantic Ocean and thus made available for the organic cycle. These are: (1) upwelling resulting from offshore trade winds off the African coast; (2) upwelling of deep Atlantic water in the Antarctic ; (3) upwelling in the boundary between currents as in the Arctic polar front; and (4) winter convection in high latitudes. The present note is intended to direct attention to an additional and hitherto unrecognized mechanism which would appear to accomplish the same end and particularly to maintain the high fertility of the waters of the eastern coast of North America.

In a paper entitled "The Dynamics of Steady Ocean Currents in the Light of Experimental Fluid Mechanics", Rossby ${ }^{3}$ has shown that the Gulf Stream may be likened to a wake stream discharging into the upper layers of a stratified medium. A wake stream, which appears to be a divergent current, is actually drawing in water from the surroundings. In a stratified medium the boundary between the layers must dip down towards the right in the northern hemisphere, as the isopycnics are observed to do in sections across the Gulf Stream, and this dip is to be regarded as the result rather than the cause of the current flow. The compensating movements set up in the surroundings of a wake stream must have a component in the direction of the current itself on the right side. The Antilles current appears to be such a compensating current. On the left side, the compensating movements must appear as a counter current, represented by the slope water of the American coast.

It is brought out that the absorption of water into the wake stream must take place primarily along the right edge, and that water will be ejected from the wake stream into the counter current. It results that water may be transferred across the current from the open ocean basins to the right into the limited body of water to the left of the current. This lateral transport must take place principally along isopycnies, which are known to slope sharply as they cross the Gulf Stream. Water is thus carried upward as well as shoreward as the result of the primary stream.

The observations of Seiwell ${ }^{4}$ on the distribution of oxygen and phosphate in the north Atlantic make it clear that the apparent site of maximal decomposition of organic matter lies much closer to the surface (250 metres) in the continental slope water than in

* Contribution No. 122 from the Woods Hole Oceanographic Institution. mid-ocean (800 metres). Such a large difference cannot reasonably be ascribed to differences in the rate of sinking or of decomposition of organisms in the contrasted localities. The findings are, however, entirely consistent with the wake stream theory developed by Rossby, since on this view the slope water is derived in considerable part from water absorbed at a greater depth along the offshore edge of the Gulf Stream. The close correlation which may be observed in a section across the Gulf Stream be. tween the conservative properties of temperature and salinity, on one hand, and the properties of biological origin such as oxygen, phosphate and nitrate concentration, on the other, suggests that the observed distribution of the latter is the result of hydrographic factors rather than biological action in situ. The products of decomposition which appear at a depth of 200-300 metres in the slope water may have been actually derived from a much greater depth in the open ocean.

Rossby's wake stream theory thus provides a mechanism for the transport of water rich in organic nutrients from the depths of the Atlantic basin on to the edge of the continental shelf. Here it comes within the influence of tidal mixing and winter convection, which complete the transport of nutrients to the surface. The latter stages in the process may be observed in the Gulf of Maine, into which slope water penetrates, and along the continental shelf ${ }^{5}$. Rossby's study suggests that the absorption of oceanic water into the Gulf Stream takes place chiefly south of the latitude of Chesapeake Bay; the discharge of this water at a lesser depth occurs from Chesapeake Bay to at least Nova Scotia. If his theory is correct, he has discovered a mechanism on which the fertility of the waters of the Atlantic Coast of North America must largely depend.

Harvard University, Cambridge, Massachusetts.

${ }^{1}$ A. Nathansohn, Abhand. Konigl. sachs Gesel. der Wissensch. Leipsig, 39,3 (1906).

${ }_{2}^{2}$ C. W. Correns, A. Defant, F. Gessner, W. Stahlberg. V. Schubert, H. Wattenberg and B. Wüst, "Tiefseebuch" (Berlin, 1934).

s C. G. Rossby, "Papers in Physical Oceanography and Meteorology", 5, No. 1 (1936)

'H. R. Seiwell, "Papers in Physical Oceanography and Meteorology", 3, No. 1 (1934). ibid., 3, No. 4.

"Papers in Physical Oceanography and Mreteorology", 2, No. 4 .

\section{Devernalization of Winter Rye by High Temperature}

ALthough the effect of low temperature in inducing vernalization is now well established, it is by no means clear to what this effect is due. It appeared possible that the mere check in growth at low temperature is the chicf factor. The results of Vasiljev ${ }^{1}$, which showed that when the period of low temperature treatment is included the time taken to flower remains nearly constant, lends support to this view.

Experiments were therefore performed in which growth was checked by keeping the imbibed grain in an atmosphere of nitrogen for varying periods of time. At low temperature $\left(1^{\circ} \mathrm{C}\right.$.) this may be ex. tended to twelve weeks, and the seeds on exposure to air are viable and produce normal plants. They are, however, unvernalized. At $20^{\circ} \mathrm{C}$. the seed does not remain viable if the continuous anærobic period extends for more than three weeks. After such a period of checked growth, the further time required to flower is equal to that required by untreated plants. 